\title{
Nodule Count, End of Solidification Cooling Rate, and Shrinkage Porosity Correlations in High Silicon Spheroidal Graphite Iron
}

\author{
Gorka Alonso $^{1, *}$, Doru Michael Stefanescu ${ }^{2}$ D , Beñat Bravo ${ }^{1}$, Gorka Zarrabeitia ${ }^{1}$ and Ramon Suarez ${ }^{1,3}$ \\ 1 AZTERLAN, Basque Research and Technology Alliance (BRTA), 48200 Durango, Spain; \\ bbravo@azterlan.es (B.B.); gzarrabeitia@azterlan.es (G.Z.); rsuarez@azterlan.es (R.S.) \\ 2 The Ohio State University, Columbus, $\mathrm{OH}$ and The University of Alabama, Tuscaloosa, AL 35487, USA; \\ stefanescu.1@osu.edu \\ 3 Veigalan Estudio 2010 S.L.U., 48200 Durango, Spain \\ * Correspondence: galonso@azterlan.es
}

check for updates

Citation: Alonso, G.; Stefanescu, D.M.; Bravo, B.; Zarrabeitia, G.; Suarez, R. Nodule Count, End of Solidification Cooling Rate, and Shrinkage Porosity Correlations in High Silicon Spheroidal Graphite Iron. Minerals 2021, 11, 155.

https://doi.org/10.3390/min11020155

Academic Editor: Brajendra Mishra

Received: 8 January 2021

Accepted: 28 January 2021

Published: 1 February 2021

Publisher's Note: MDPI stays neutral with regard to jurisdictional claims in published maps and institutional affiliations.

Copyright: (c) 2021 by the authors. Licensee MDPI, Basel, Switzerland. This article is an open access article distributed under the terms and conditions of the Creative Commons Attribution (CC BY) license (https:// creativecommons.org/licenses/by/ $4.0 /)$.

\begin{abstract}
High-silicon spheroidal graphite (SG) irons present higher changes of density during the solidification process when compared to normal SG irons. This special behavior is particularly significant in the last stages of solidification, where the graphite expansion may become insufficient to compensate the contraction of the austenite and the risk of microporosity formation increases. The goal of this laboratory research was to establish correlations between the different levels of nodule count obtained using five commercial inoculants, the cooling rate at the end of solidification, and the shrinkage porosity propensity. The analysis was conducted on thermal analysis cups that were sectioned and evaluated for microstructure by optical metallography and by 2D analysis with the Image J software to quantify the size of the microporosity region. It was found that a higher nodule count, associated with higher cooling rate at the end of solidification, generates lower porosity. SEM analysis was conducted to study the nature of nuclei. Complex (MgSiAl) N nitrides were found as the main nucleation sites for graphite.
\end{abstract}

Keywords: high-silicon spheroidal graphite; inoculants; microporosity; nuclei; nitrides

\section{Introduction}

Because of the increased tendency to develop shrinkage defects, high-Si spheroidal graphite iron (SGI) presents significant challenges to the production of sound castings. The interplay between dendrite shrinkage and graphite expansion produces several shrinkage defects illustrated in Figure 1 [1]. Some of these defects are the result of uncompensated shrinkage (pipe, caved surfaces), some are produced by a decrease in the gas solubility in the liquid alloy (center-line microporosity) or from the mold/metal interface interaction (surface microporosity), and some can be the result of both shrinkage and gas porosity (macroporosity or enclosed shrinkage).

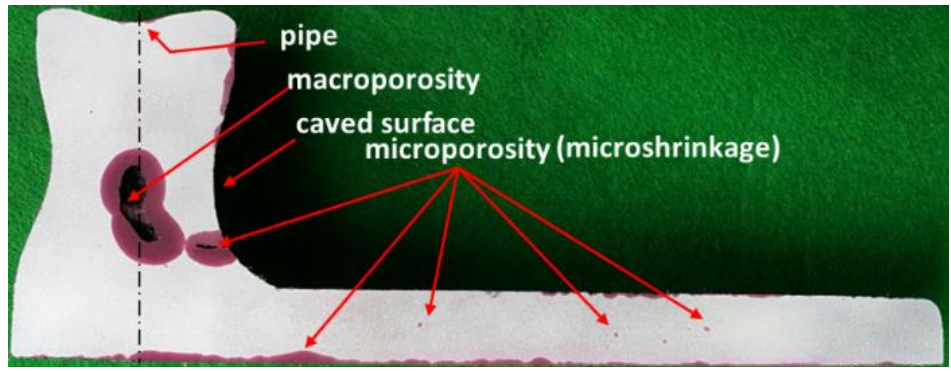

Figure 1. Various types of shrinkage defects found in an experimental casting [1]. 
The literature provides abundant information on the negative effects of porosity on tensile strength, elongation, fatigue life, and hot tear initiation, particularly in the case of aluminum-based alloys (see, for example, the summary in ref. [2]). It stands to reason that understanding porosity formation and the development of subsequent processes that can lead to its elimination in casting is not only a promising quality improvement route, but also a cost saving endeavor.

Shrinkage occurrence can be understood with the help of Figure 2 [3]. Immediately after pouring, the liquid iron cools, liquid shrinkage occurs as the density of the liquid increases, and its specific volume decreases. This shrinkage is compensated by the risers. In a hypoeutectic iron, solidification then starts at $T L$ with the formation of dendrites that grow inward from the walls of the cup until the start of the eutectic solidification (Zone 1 on the figure). This shrinkage can also be compensated by the riser as long as the feeding channel is open. Dendritic shrinkage can extend even after the beginning of solidification, (TE_start), as the amount of eutectic produced increases slowly over time (Zone 2). After the maximum undercooling is reached (TE_low), fast generation of eutectic shifts the emphasis of solidification from dendritic-dominated (Zones 1 and 2) to graphitedominated (Zones 3 and 4). In Zone 3, graphite expansion compensates for liquid and dendrite shrinking. However, in Zone 4, when the amount of eutectic generated and thus that of the graphite decreases, there is a risk of microshrinkage (microporosity) formation, because graphite expansion may become insufficient to compensate the shrinkage.

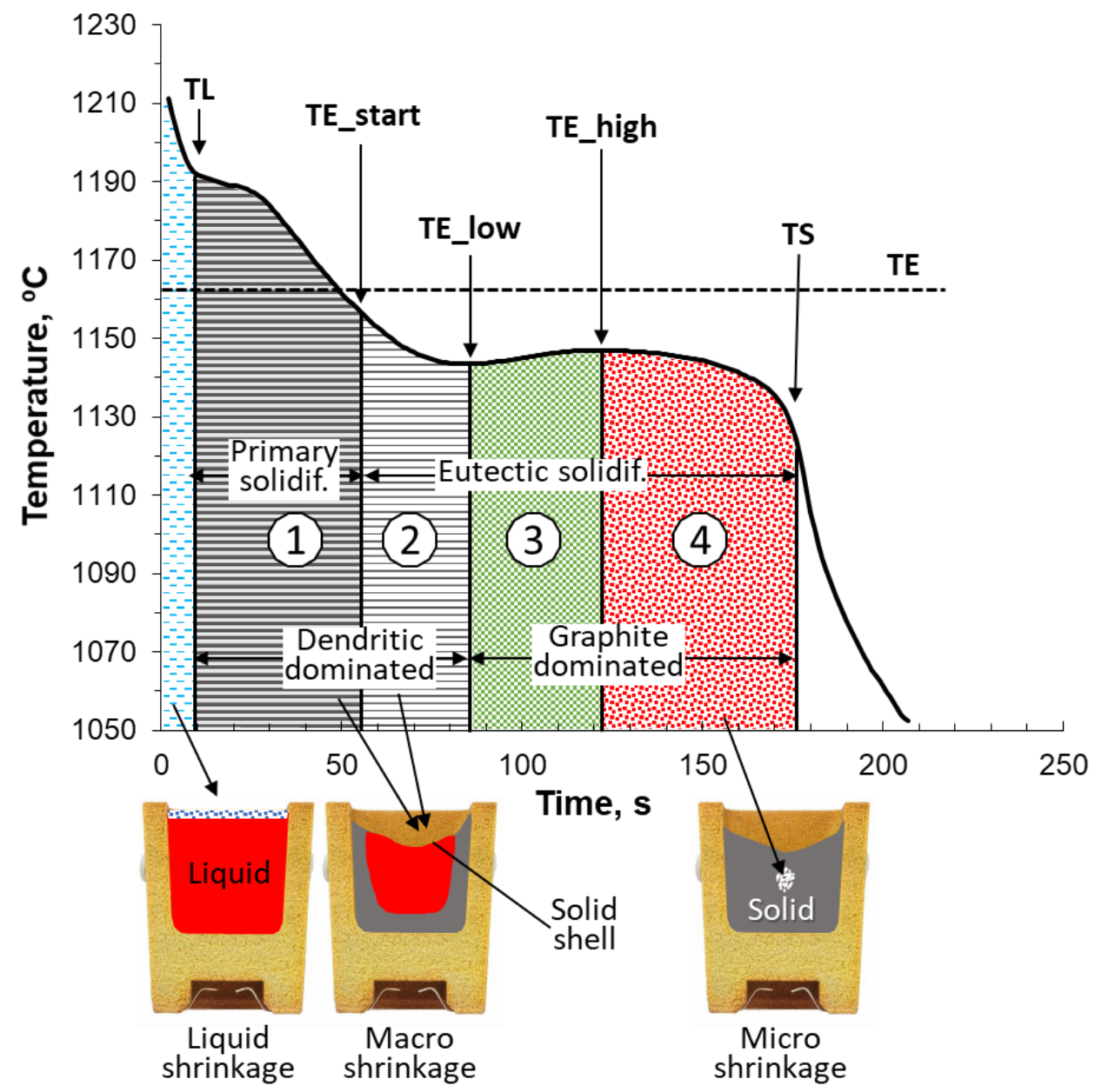

Figure 2. Cooling curve of a hypoeutectic iron with characteristic temperatures showing solidification ranges for primary and eutectic phases and correlation with shrinkage defect formation [3]. 
During primary solidification of hypoeutectic iron, in the dendrite-dominated solidification (Figure 2), the liquid/austenite mixture continues to shrink as the specific volume decreases (Figure 3). As long as the permeability of the mushy dendritic region is sufficiently high, the shrinkage is compensated by flow from the risers. Graphite expansion begins once the maximum undercooling, $T E \_l o w$, is reached and may (green line), or may not (red line), continue to the end of solidification. The final result will be expansion if enough graphite expansion occurs, or shrinkage in the case of insufficient expansion, as shown in the critical range in Figure 3. The figure also shows a drop in expansion (green line) at the end of solidification, typically produced by decreased graphite growth in the last regions to solidify because of segregation of carbide-promoting elements. For SG iron, the mushy zone is much larger and its permeability much smaller than that of lamellar graphite (LG) iron. This restricts feeding from the riser and decreases the cooling rate. In principle, both LG and SG irons of near-eutectic or eutectic composition should exhibit expansion during solidification and therefore should not be prone to forming either cavity or porosity shrinkage. While this is true for gray iron, the ordinary manufacturing of SG iron is susceptible to shrinkage porosity because of limited graphite growth at the end of solidification, which is then dominated by austenite shrinkage. This induces specific volume decrease and produces uncompensated shrinkage in the last region to solidify, and thus porosity.

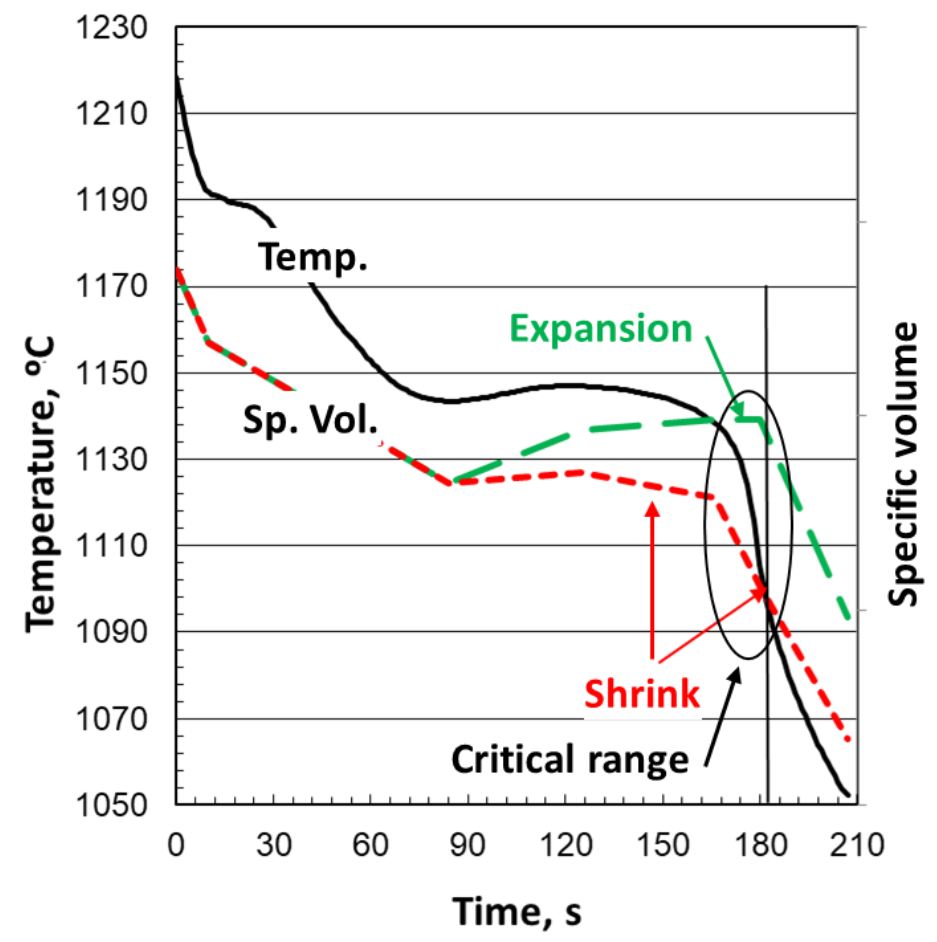

Figure 3. Temperature and specific volume evolution during the solidification of cast iron [3].

The fracture pressure in liquid state is very high; therefore, porosity cannot form without the existence of gas pores in the liquid. Indeed, according to Tiryakioglu [4], the intrinsic fracture pressure of aluminum is of $-4 \mathrm{GPa}$ at its melting temperature in both liquid and solid states. The nucleation of pores that form porosity is the subject of some debate. The matter is addressed in depth for the case of steel and aluminum alloys, where some researchers attribute pore nucleation to either homogeneous or heterogeneous nucleation [1,5-9]. They contend that nucleation of gas bubbles before the beginning of solidification occurs at the mold walls and on impurities in the liquid, and that micron-size gas bubbles can be assumed to exist in the liquid following their incorporation from the turbulent flow during pouring and mold filling. However, some studies [2] maintain that pores cannot nucleate either homogeneously or heterogeneously in liquid aluminum. 
Indeed, results of in situ studies on pore formation show that pores appear at low hydrogen supersaturation levels, bypassing nucleation completely [2]. They support Campbell's theory, according to which pores are formed by oxide bifilms [10-14]. Moreover, Campbell even extended his theory to SG iron [15].

The purpose of this article, however, is not to debate the origins of pore formation, but rather to process improvement by quantifying the size of microporosity in SG iron as a function of the chemical composition of the inoculants used.

\section{Experimental Procedure}

A cast iron heat (\#230120) with high carbon equivalent $(\mathrm{CE}=4.73)$ was produced in a $100 \mathrm{~kg}$ medium frequency induction furnace $(250 \mathrm{~Hz}, 100 \mathrm{Kw})$. The charge of this heat consisted of $24 \mathrm{~kg}$ of high silicon ductile iron returns and $26 \mathrm{~kg}$ of high purity iron. Predetermined amounts of a commercial graphite $(98.9 \%$ C, $0.03 \%$ S) and of FeSi75 alloy $(74.6 \% \mathrm{Si}, 0.3 \% \mathrm{Ca}, 0.7 \% \mathrm{Al})$ were also added to the metallic charges. A small quantity of pure antimony $(99.99 \% \mathrm{Sb})$ was introduced, in order to avoid the formation of chunky graphite. After superheating to $1500{ }^{\circ} \mathrm{C}$, the iron was transferred into the pouring ladle for $\mathrm{Mg}$ treatment (sandwich method, 1.1 mass $\%$ of the batch weight, covered with steel scrap) with an Fe-Si-Mg alloy having the chemical composition $46 \% \mathrm{Si}, 6.06 \% \mathrm{Mg}, 0.56 \%$ $\mathrm{Ca}, 1.03 \% \mathrm{Al}$, and no rare earth (RE).

The final melt composition (mass $\%$ ) was as follows: $3.38 \% \mathrm{C}, 4.08 \% \mathrm{Si}, 0.18 \% \mathrm{Mn}$, $0.014 \%$ P, $0.007 \%$ S, $0.044 \%$ Cr, $0.01 \%$ Mo, $0.091 \% \mathrm{Ni}, 0.042 \% \mathrm{Mg}, 0.01 \% \mathrm{Ti}$, and $0.0045 \% \mathrm{Sb}$.

A $0.2 \mathrm{mass} \%$ of commercial inoculant was deposited on the bottom of the thermal analysis (TA) cups before filling. A number of experiments were conducted, the first one without inoculation and the following five with different inoculants. The chemical compositions of the inoculants are listed in Table 1. For each experiment, the cooling curves of the TA cups were recorded with the Thermolan ${ }^{\circledR}$ system (V2, Veigalan Estudio 2010, S.L.U, Durango, Spain), and the cooling rates (first derivatives of the cooling curves) were calculated and plotted. The TA cups were sectioned in the middle, with the objective to detect higher shrinkage evaluated through quantitative visual microscopy (image J) for nodule count and graphite shape (roundness). A 2D analysis with the Image J software was also conducted to quantify the size of the microporosity region. The analysis does not account for the size of the caved surfaces. To identify possible nuclei, an Ultra PLUS Carl Zeiss SMT (ZEISS, Thornwood, NY, USA) $(0.8 \mathrm{~mm}$ resolution at $30 \mathrm{kV})$ in the STEM mode was used in combination with an X-Max 20 Oxford Instruments EDX detector (Oxford Instruments, Abington, UK) with a resolution of $127 \mathrm{eV} / \mathrm{mm}^{2}$. The most advanced FEGSEM techniques such as spectra, mappings, and line scans, were applied to analyze the main elements present in the inclusions and to estimate the type of compounds which can act as nucleation sites for graphite.

Table 1. Chemical analysis of inoculants, mass\% (bold numbers were used for inoculant symbol).

\begin{tabular}{ccccccccccc}
\hline Inoculant & $\mathbf{S i}$ & $\mathbf{A l}$ & $\mathbf{C a}$ & $\mathbf{M n}$ & $\mathbf{T i}$ & $\mathbf{Z r}$ & $\mathbf{C e}$ & $\mathbf{B a}$ & $\mathbf{M g}$ & $\mathbf{B i}$ \\
\hline $0.5 \mathrm{Ba} 0.3 \mathrm{Bi}$ & 70.0 & 0.82 & 1.49 & 0.15 & 0.10 & $<0.05$ & 0.20 & $\mathbf{0 . 5 3}$ & $<0.10$ & $\mathbf{0 . 3 5}$ \\
$1.8 \mathrm{Ce}$ & 72.2 & 0.95 & 0.91 & 0.20 & 0.07 & 0.11 & $\mathbf{1 . 8 3}$ & & \\
$1 \mathrm{Ba}$ & 76.5 & 0.80 & 1.10 & & & & & $\mathbf{1 . 0 2}$ & \\
$6.8 \mathrm{Zr} 6 \mathrm{Mn} 0.6 \mathrm{Ba}$ & 62.6 & 1.01 & 1.79 & $\mathbf{5 . 9 6}$ & 0.13 & $\mathbf{6 . 7 7}$ & $<0.05$ & $\mathbf{0 . 6 5}$ & 0.22 & $<0.02$ \\
$2.9 \mathrm{Al}$ & 70.5 & $\mathbf{2 . 9 0}$ & 0.90 & & & & $<0.05$ & & $<0.01$ & \\
\hline
\end{tabular}

\section{Experimental Results and Discussion}

The experimental results for the exploratory laboratory experiments are summarized in Table 2. Some examples of the cooling curve analysis of the various TA cups are given in Figure 4. It is seen that while all the samples have the same initial cooling rates (Figure 4a), there are significant differences in their maximum cooling rates at the end of solidification (minima of the first derivatives on Figure $4 b$ ). 
Table 2. Experimental results.

\begin{tabular}{|c|c|c|c|c|c|}
\hline Sample \# & Inoculant & Nod. ct. $\left(\mathrm{mm}^{-2}\right)$ & Roundness & Shrink Porosity (\%) & $C R_{\operatorname{Max}}\left({ }^{\circ} \mathrm{C} / \mathrm{s}\right)$ \\
\hline 1 & none & 447 & 0.80 & 7.46 & 2.82 \\
\hline 2 & $0.5 \mathrm{Ba} 0.3 \mathrm{Bi}$ & 480 & 0.80 & 2.10 & 3.25 \\
\hline 3 & $1.8 \mathrm{Ce}$ & 709 & 0.78 & 0.88 & 3.98 \\
\hline 4 & $1 \mathrm{Ba}$ & 619 & 0.83 & 1.09 & 4.09 \\
\hline 5 & 6.8Zr6Mn0.6Ba & 490 & 0.77 & 2.39 & 3.70 \\
\hline 6 & $2.9 \mathrm{Al}$ & 489 & 0.80 & 2.32 & 3.13 \\
\hline
\end{tabular}

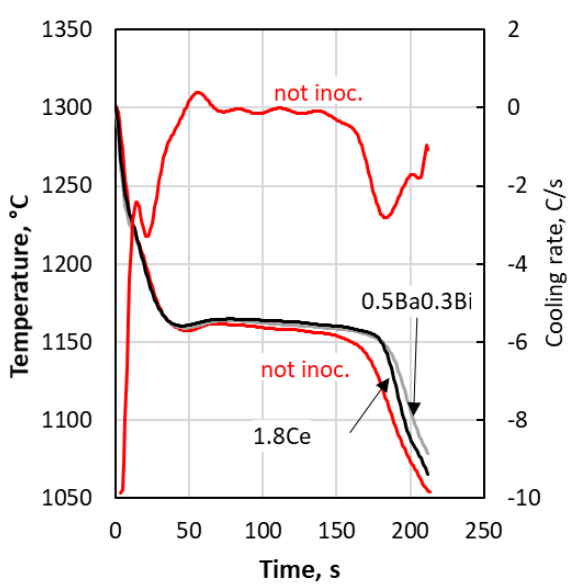

(a)

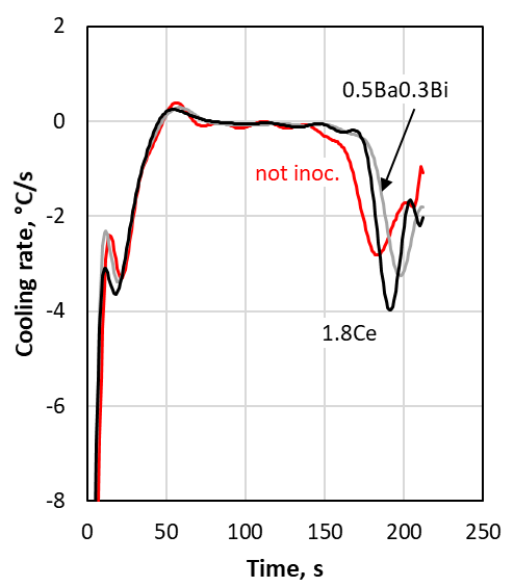

(b)

Figure 4. Examples of cooling curves and their first derivatives (cooling rates) for the experimental samples: (a) cooling curves for three samples and cooling rate for the not inoculated sample, (b) cooling rates for three samples.

The detailed analysis of the shape and size distribution of graphite nodules revealed that although the graphite shape (roundness) was not too different between the samples (Table 2), the size distribution of the inoculated samples moved to finer graphite as expected (Figure 5), probably due to the high local concentrations of $\mathrm{Si}$, which increased the activity of $C$ favoring the formation of graphite. The most efficient inoculants based on the number of graphite nodules produced were Re-1.8Ce and Ilard-1Ba, with 709 and $619 \mathrm{nod} / \mathrm{mm}^{2}$, respectively. However, the analysis of the size distributions in Figure 5 reveals that while the $1.8 \mathrm{Ce}$ inoculant produced a distribution with $90 \%$ of the nodules in the range of 5-15 $\mu \mathrm{m}$ diameter, only $77 \%$ of the nodules in the sample showing the results for the $1 \mathrm{Ba}$ inoculant were in this range. Additionally, the nodule size was more uniform for the $1.8 \mathrm{Ce}-$ inoculated irons than for the 1Ba iron (four columns with more than $1 \%$ vs. five columns, respectively). The least efficient inoculant appeared to be $2.9 \mathrm{Al}$, with a distribution spread over seven columns.

Sections of the TA cups are presented in Figure 6, with the corresponding 2D analysis with the Image J software results for porosity in percentage. Both visual estimation and 2D image analysis results applying techniques based on contrast and grey levels analysis demonstrate that the addition of inoculants drastically reduced the shrinkage porosity. Indeed, the uninoculated sample exhibited $7.46 \%$ porosity, while the inoculated samples were all under $2.39 \%$. Two major differences between the uninoculated and the inoculated samples are seen when analyzing the nodule count distribution graphs:

- The inoculated samples have a higher overall nodule count $\left(480-709 \mathrm{~mm}^{-2}\right.$ for inoculated, compared to $447 \mathrm{~mm}^{-2}$ for uninoculated).

- For all inoculated samples, the higher frequency of nodule distribution was for nodule diameters of 5-10 $\mu \mathrm{m}$, while for the uninoculated sample it was in the range 10-15 $\mu \mathrm{m}$. 

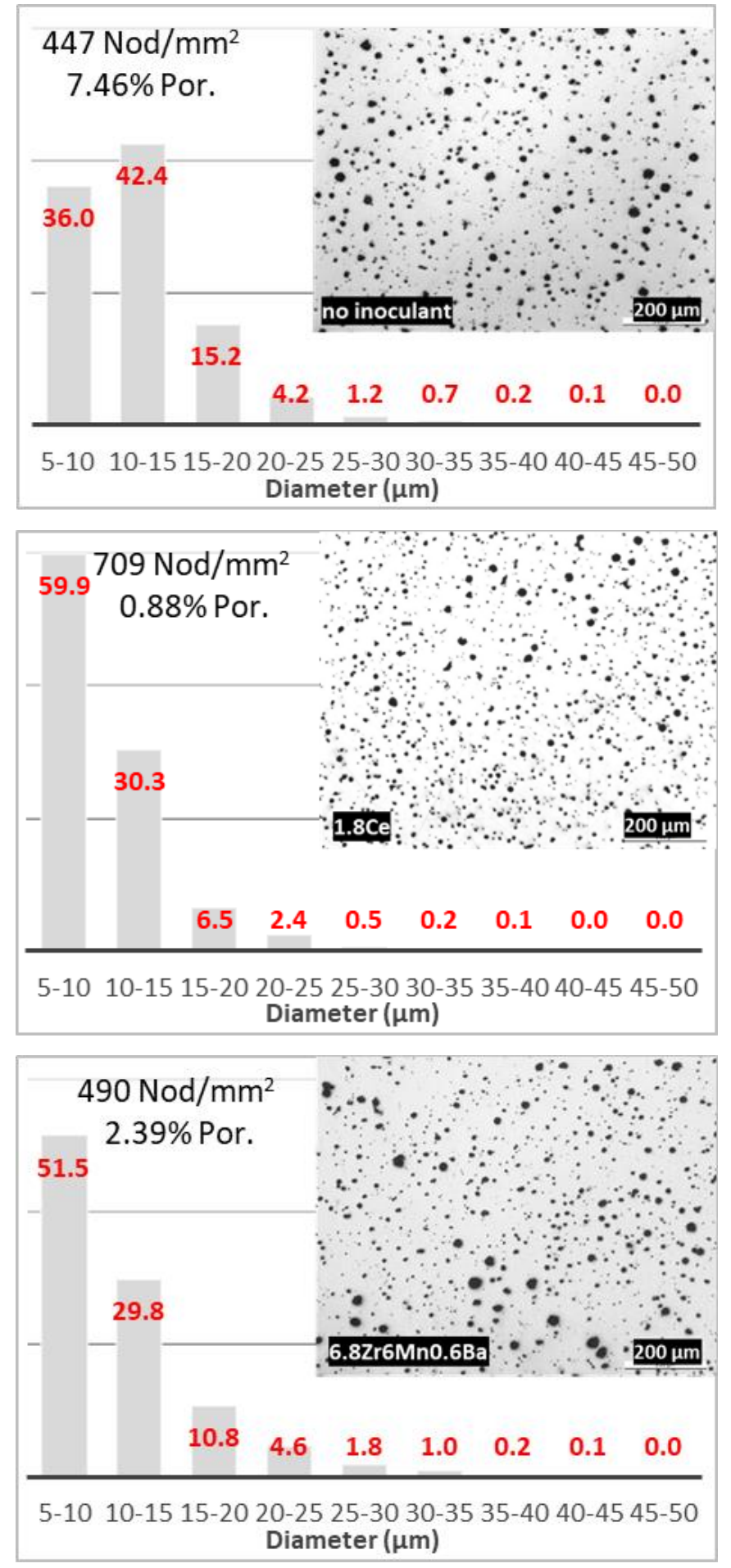
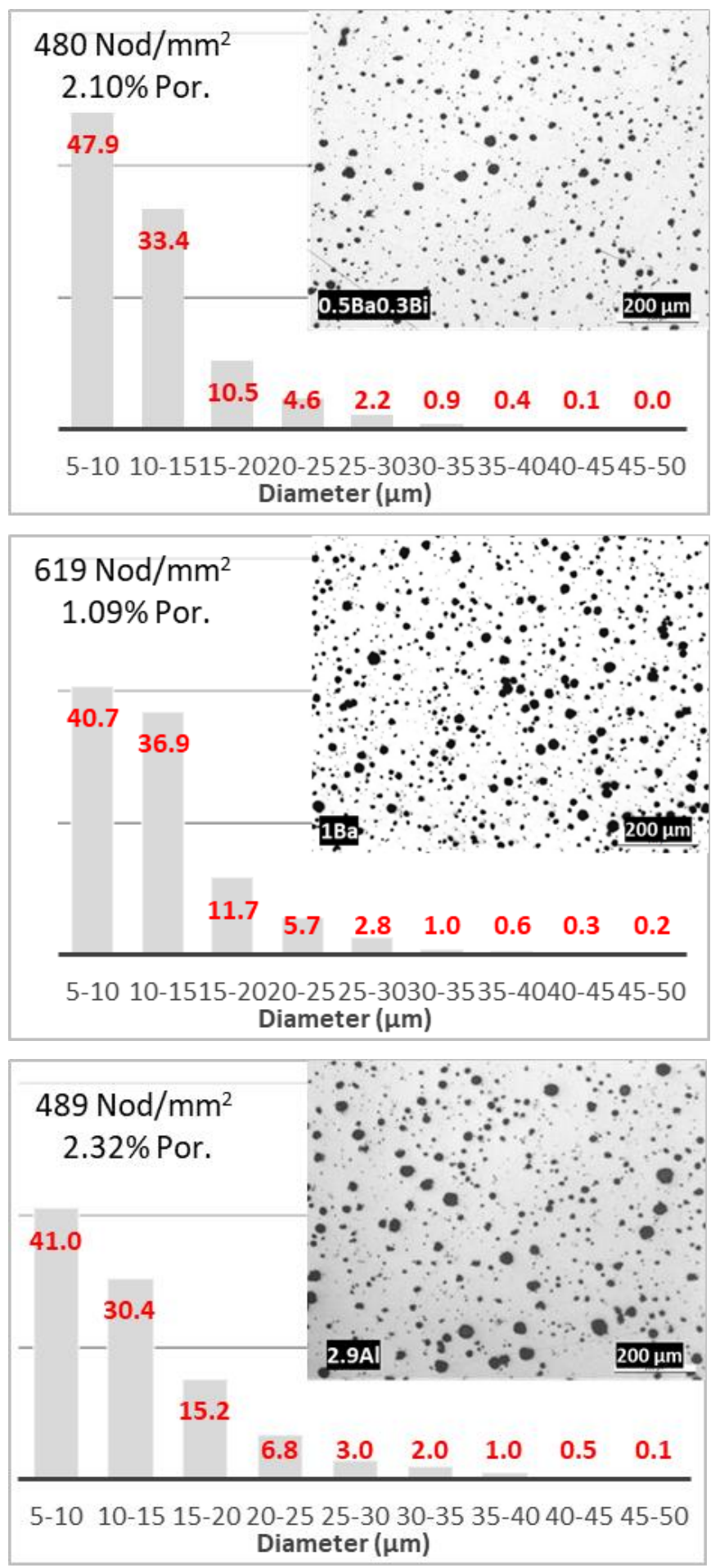

Figure 5. Unetched micrographs and graphite size distribution; the $y$-axis is the $\%$ nodules. 


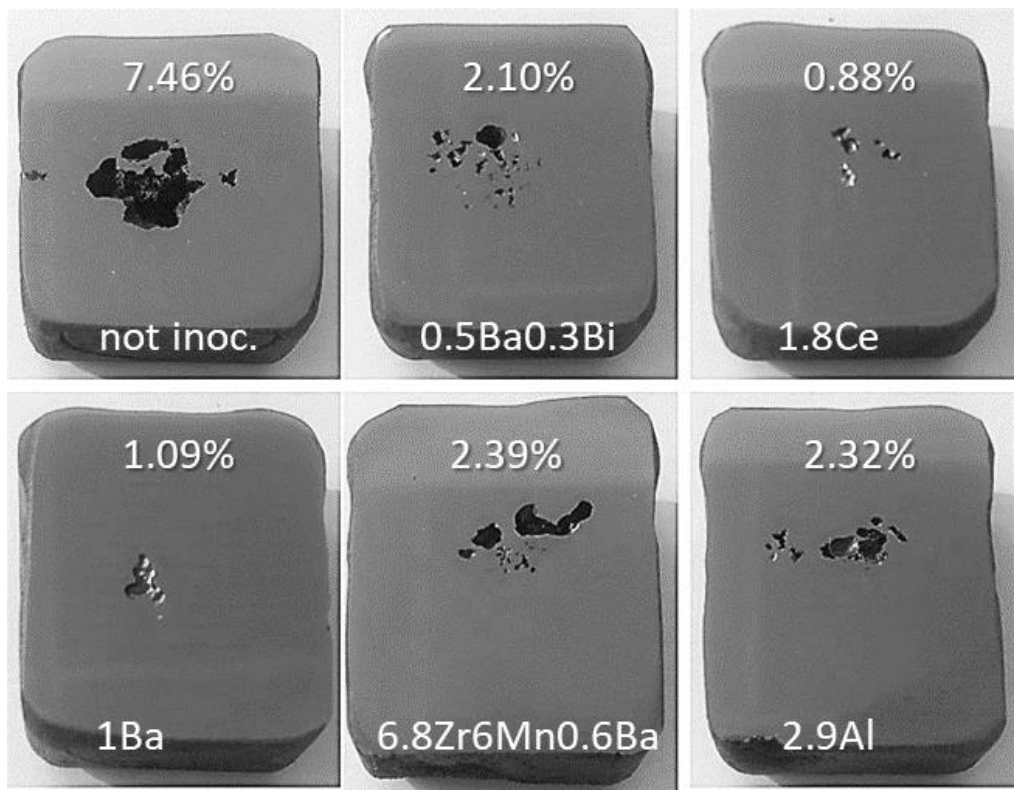

Figure 6. Images of sections through the middle of the thermal analysis (TA) cups with the corresponding porosity obtained from 2D image analysis measurements.

The lowest porosity was measured on the TA cup inoculated with the 1.8Ce inoculant. A graphic summary of the experimental data is presented in Figure 7. From Table 2 and this figure, it is seen that there is a clear correlation between shrinkage porosity on one hand, and the nodule count and the maximum cooling rate at the end of solidification $\left(C R_{\max }\right)$, on the other hand. First, we note on Figure $7 \mathrm{a}$ that that the uninoculated sample had the lowest nodule count $\left(447 \mathrm{~mm}^{-2}\right)$ as expected, and additionally, by far the highest porosity $(7.46 \%)$. All inoculants decreased in porosity dramatically. Then, from Figure $7 \mathrm{~b}$, it can be observed that the porosity appears to be well correlated with the $C R_{\max }$, which increased as the porosity decreased. The increase in the maximum cooling rate with porosity was probably due to the fact that higher porosity decreased the thermal conductivity of the TA sample, and therefore the slope of the cooling curve. This is also illustrated on Figure 4a, where it is seen that the end of the cooling curve of the $1.8 \mathrm{Ce}$ inoculant ( $0.88 \%$ porosity) is steeper than those of the $0.5 \mathrm{Ba} 0.3 \mathrm{Bi}$ inoculant $(2.1 \%$ porosity) and of the no-inoculant ( $7.46 \%$ porosity) cups. There is also a reasonable correlation between the nodule count and $C R_{\max }$ (Figure 7c).
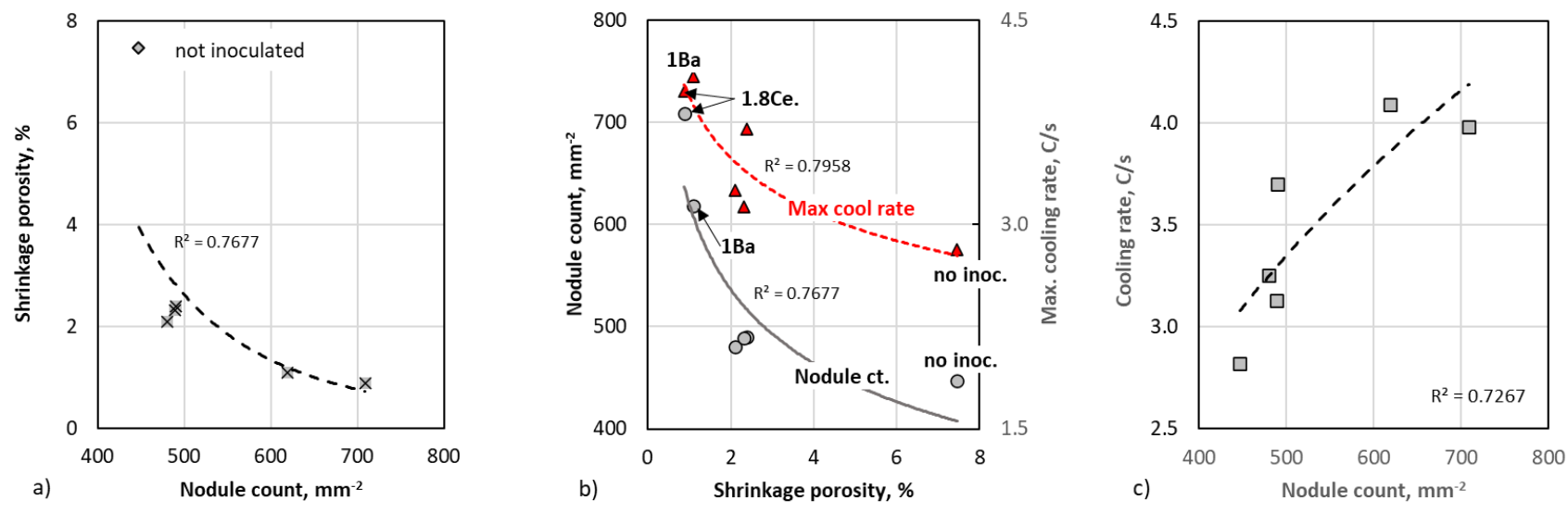

Figure 7. Correlation between shrinkage porosity, nodule count, and the maximum cooling rate at the end of solidification $\left(C R_{\max }\right)$. 
The information provided by the SEM analysis indicates that (MgSiAl)N nitrides are the predominant inclusions for all samples. They present a clear cubic and/or polygonal shape and usually appear alone as nucleation sites for graphite (Figure 8a). Some sulfides nucleating on small $\mathrm{Mg}$ oxides were also observed (Figure $8 \mathrm{~b}$ ). No Ti carbides were found because of the low level of titanium $(0.010 \% \mathrm{Ti})$ in the base metal [16]. Several phosphides were detected (typically in the uninoculated sample) acting always as nuclei for small spiky graphite [17].
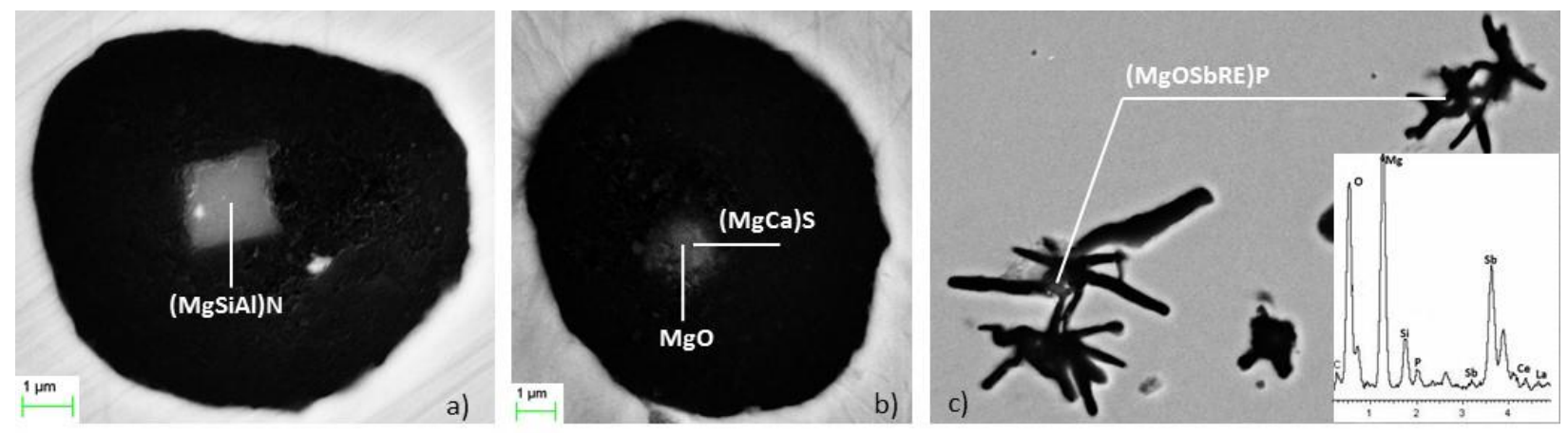

Figure 8. Type of inclusions acting as nuclei: (a) (MgSiAl)N nitrides in spheroidal graphite (SG); (b) combination of oxide/sulfide in SG; (c) complex phosphides, with superimposed WDX/SEM spectrum analysis for spiky graphite.

\section{Conclusions}

The correlation between the shrinkage porosity and some metallographic and thermal analysis parameters of $4.08 \% \mathrm{Si}$ spheroidal graphite iron was evaluated on thermal analysis cups poured from the same $\mathrm{Mg}$-treated iron. Commercial inoculants were added in the cups prior to filing, except for one cup that was used as a reference. All inoculants decreased the shrinkage porosity tendency by at least a factor of three. The best inoculants in terms of shrinkage porosity area on the sectioned TA cups were Re- $1.8 \mathrm{Ce}(1.83 \% \mathrm{Ce}, 0.11 \% \mathrm{Zr})$ and Ilard-1Ba $(1.82 \% \mathrm{Ba})$. The lowest porosity area was associated with the highest maximum of the cooling rate at the end of solidification and with the highest nodule count.

The preceding discussion and conclusions are based on the limited data obtained from laboratory experiments. The addition of inoculants on the bottom of TA cups is not a standard inoculation method and may have contributed to the data scattering. To confirm these results, a full-scale industrial investigation is necessary.

Author Contributions: Conceptualization, D.M.S. and G.A.; methodology, D.M.S.; software, B.B.; validation, G.A., B.B. and G.Z.; formal analysis, D.M.S.; investigation, G.A.; resources, G.A.; data curation, G.A.; writing —original draft preparation, D.M.S. and G.A.; writing—review and editing, D.M.S. and G.A.; visualization, G.A.; supervision, R.S.; project administration, R.S. All authors have read and agreed to the published version of the manuscript.

Funding: This research received no external funding.

Acknowledgments: This work was supported by Diputacion Foral de Bizkaia, Spain.

Conflicts of Interest: The authors declare no conflict of interest.

\section{References}

1. Kweon, E.S.; Roh, D.H.; Kim, S.B.; Stefanescu, D.M. Computational modeling of shrinkage porosity formation in spheroidal graphite iron: A proof of concept and experimental validation. Int. J. Met. 2020, 14, 601-609. [CrossRef]

2. Tiryakioğlu, M. The Effect of Hydrogen on Pore Formation in Aluminum Alloy Castings: Myth Versus Reality. Metals 2020, 10, 368. [CrossRef]

3. Stefanescu, D.M.; Suarez, R.; Kim, S.B. 90 years of thermal analysis as a control tool in the melting of cast iron. China Foundry 2020, 17, 69-84. [CrossRef]

4. Tiryakioglu, M. On the intrinsic fracture pressure of liquid and solid aluminum around its melting temperature. Met. Mater. Trans. A 2018, 49, 5953-5955. [CrossRef] 
5. Kubo, K.; Pehlke, R.D. Mathematical modeling of porosity formation in solidification. Met. Mater. Trans. B 1985, $16 B, 359-366$. [CrossRef]

6. Sung, P.K.; Poirier, D.R.; Felicelli, S.D. Continuum model for predicting microporosity in steel castings. Model. Simul. Mater. Sci. Eng. 2002, 10, 551-568. [CrossRef]

7. Khalajzadeh, V.; Carlson, K.D.; Backman, D.G.; Beckermann, C. A pore-centric model for combined shrinkage and gas porosity in alloy solidification. Met. Mater. Trans. A 2017, 48, 1797-1816. [CrossRef]

8. Felicelli, S.D.; Wang, L.; Pita, C.M.; De Obaldia, E.E. A Model for Gas Microporosity in Aluminum and Magnesium Alloys. Meter. Mater. Trans. 2009, 40B, 169-181. [CrossRef]

9. Yamamoto, T.; Komarov, S.V. Development of a numerical model for hydrogen bubble generation, dynamics and trapping during solidification of aluminium alloys through eulerian-lagrangian framework. Int. J. Cast Met. Res. 2019, 32, 266-277. [CrossRef]

10. Campbell, J. Review: Defect Structure of Liquid Metals. In Modeling of Casting, Welding, and Advanced Solidification Processes-XII: Preface; Stefanescu, D.M., Cockcroft, S.L., Eds.; TMS: Warrendale, PA, USA, 2003; pp. 209-219.

11. Dai, X.; Yang, X.; Campbell, J.; Wood, J. Influence of oxide film defects generated in filling on mechanical strength of aluminium alloy castings. Mater. Sci. Technol. 2004, 20, 505-513. [CrossRef]

12. Mi, J.; Harding, R.A.; Campbell, J. Effects of the entrained surface film on the reliability of castings. Met. Mater. Trans. A 2004, 35, 2893-2902. [CrossRef]

13. Campbell, J. Entrainment defects. J. Mater. Sci. Technol. 2006, 22, 127-145. [CrossRef]

14. Tiryakioğlu, M.; Yousefian, P.; Eason, P.D. Quantification of entrainment damage in a356 aluminum alloy castings. Met. Mater. Trans. A 2018, 49, 5815-5822. [CrossRef]

15. Campbell, J. The Structure of Cast Irons. Mater. Sci. Forum 2018, 925, 86-89. [CrossRef]

16. Alonso, G.; Stefanescu, D.M.; De La Fuente, E.; Larrañaga, P.; Suarez, R. The Influence of Trace Elements on the Nature of the Nuclei of Graphite in Ductile Iron. Mater. Sci. Forum 2018, 925, 78-85. [CrossRef]

17. Alonso, G.; Stefanescu, D.M.; Suarez, R. Effect of Antimony on the Nucleation Process of Spheroidal Graphite Iron. In Proceedings of the AFS Proceedings 124th Metalcasting Congress, Cleveland, OH, USA, 21-23 April 2020. 